Bangladesh J. Plant Taxon. 17(1): 97-99, 2010 (June)

(C) 2010 Bangladesh Association of Plant Taxonomists

\title{
ETHNOBOTANICAL INFORMATION ON SAPIUM INSIGNE (ROYLE) BENTH.: A CONSERVED PLANT OF SHIVALIK HILLS, INDIA
}

\author{
Dhiraj S. Rawat and Anjna D. KharwaL* \\ Deparment of Botany, Shoolini Institute of Life Sciences and \\ Business Management, Solan (H.P.), India
}

Keywords: Ethnobotanical information; Latex; Shivalik hills.

Shivalik hills or the lower hills of Himachal Pradesh in ancient times were known as 'Manak Parbat'. It literally means the "tresses of Shiva". Shivalik hills in Himachal Pradesh includes districts i.e. Kangra, Hamirpur, Una, Bilaspur and the lower parts of Mandi, Solan and Sirmaur. The altitude ranges from 350m to 1,500m above the sea level, (Balokhra, 2002). Sapium insigne (Royle) Benth. is a common medium-sized deciduous tree of this range with alternate, toothed, oblong-lanceolate, glabrous leaves crowded towards the end of branches. Bark rough, divided deeply into furrows with corky ridges. Flowers are yellowish-green, arranged in terminal spikes. Capsules long, 3-lobed, 3seeded and fleshy when young. It mostly occurs in wastelands and along field boarders. So far a little information of latex used by locals as a fish poison is available (Ambasta, 1986; Jain, 1984, 1991). This species is of great concern in Himalayas as it is fast growing, discarded in use due to fear of latex and avoidance of plant growth near residential areas. In order to understand the ethnobotanical relationship the present study is carried out.

For a better understanding of local beliefs, habits and uses of plant, different categories of people like family heads, healers, old experienced and knowledgeable informants were repeatedly interviewed. In total 50 informants were interviewed in each district (Total 350) for one year in Shivalik hills (Kangra, Hamirpur, Una, Bilaspur and the lower parts of Mandi, Solan and Sirmaur). Specific questions based upon Proforma (Jain and Goel, 1995) were asked and the resultant information was recorded in the ethnobotanical field notebook. Information revealed the facts about its local names, ecology, reproductive cycle (flowering and fruiting period), causes of fear to locals, ethnobotanical uses if any and mode of reproduction.

Sapium insigne (Royle) Benth. (Euphorbiaceae) is locally known as 'Ainkhar' or 'Balodhar' in Shivalik hills. Flowering occurs during the months of May to July with crimson red spikes. It appears beautiful in vegetative as well as in flowering stage; but still it is highly undesirable by the locals due to its poisonous nature. It propagates through seeds. Leaves are not given as a fodder to the livestock as it is considered highly poisonous to the animals. The wood of the plant is of no use even as a fuel wood due to highly irritating smoke. It causes redness of eyes which is highly irritating. People

*Department of Botany, Govt. P. G. College, Solan (H.P.). 
consider that prolonged exposure to the smoke may lead to loss of sight. Inflammation of cornea, conjunctivitis, oedematous swellings and blisters commonly occurs on exposure to latex. Poisonous flowering spikes are of no use as such, even not touched by the locals.

The highly poisonous component of the plant is latex as stated by the locals. People fear to cut this tree as if latex happens to fall in eyes which may cause serious troubles related to eyesight. So its cutting is done with utmost care by some people as they do not want this tree to be present along the boarders of the fields as a safety measure. Latex contains fatty acid esters of tetracyclic diterpenes alcohols i.e. Phorbol and derivatives of Phorbol, Diphnane and Ingenane. The given information is the first ever report on Sapium insigne.

Similar work has been done on poisonous ivy plant (Hedera helix L.) and Brassaia actinophylla of the family Araliaceae. Oil and latex from this plant is highly irritating to skin; so people avoid them (Boyle and Harman, 1985; Massmanian et al., 1988; Mitchell, 1981).

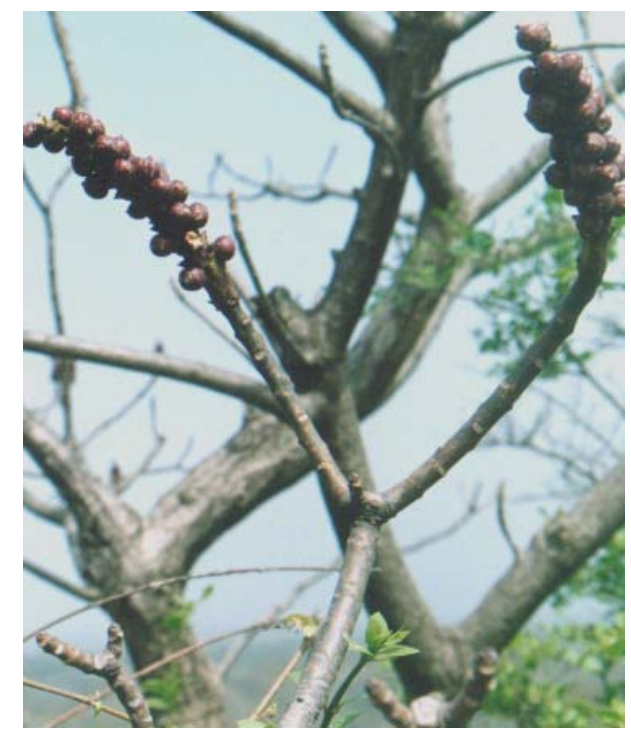

Sapium insigne (Royle) Benth. in flowering stage.

The only use of latex by locals is as a fish poison and sometimes it is applied to the boils and blisters in very little quantity to hasten suppuration (Ambasta, 1986; Jain, 1984, 1991), but utmost care is required. Some locals consider it risky to life as there are so many herbal remedies for curing later.

In this era of globalization, as people are using the natural resources ruthlessly and most of the plant species are declining but due to limited uses, poisonous nature of the latex, the population of the studied plant is increasing in this range and it seems to be automatically conserved. 


\section{Acknowledgement}

The authors are thankful to Prof. S. K. Sood, Dean of Life Sciences, Himachal Pradesh University, Shimla for his valuable guidance.

\section{References}

Ambasta, S.P. (ed.). 1986. The useful plants of India. C.S.I.R., New Delhi.

Balokhra, J.M. 2002. The wonderland Himachal pradesh. H.G. Publication, New Delhi.

Boyle, J. and Harman, R.M. 1985. Contact dermatitis to Hedera helix (common ivy). Contact Dermatitis 12: 111-112.

Jain, S.K. 1984. Ethnobotany of Morni and Kalesar (Ambala, Harayana). J. Econ. Tax. Bot. 5: 809-813.

Jain, S.K. 1991. Dictionary of Indian folk medicine and ethnobotany. Deep Publication, New Delhi.

Jain, S.K. and Goel, A.K. 1995. Workshop Exercise-1. Proforma for field work. In: Jain, S.K. (ed.). A Manual of Ethnobotany. Scientific Publ., Jodhpur. pp. 142-147.

Massmanian, A., Valcuende-Cavero, F., Ramirez-Bosca, A. and Castells-Rodellas, A. 1988. Contact dermatitis from variegated ivy (Hedera helix subsp. canariensis Willd.). Contact Dermatitis 18: 247-248.

Mitchell, J.C. 1981. Allergic contact dermatitis from Hedera helix and Brassaia actinophylla (Araliaceae). Contact Dermatitis 7: 158-159.

(Manuscript received on 5 March 2009; revised on 6 October 2009) 